\title{
Article
}

\section{Evaluating the impact of a nationally recognised training programme that aims to raise the awareness and challenge attitudes of personality disorder in multi- agency partners}

Lamph, Gary, Latham, Cameron, Smith, Debra, Brown, Andrew, Doyle, Joanne and Sampson, Mark

Available at http://clok.uclan.ac.uk/25526/

Lamph, Gary ORCID: 0000-0002-4099-2812, Latham, Cameron, Smith, Debra, Brown, Andrew, Doyle, Joanne and Sampson, Mark (2014) Evaluating the impact of a nationally recognised training programme that aims to raise the awareness and challenge attitudes of personality disorder in multi-agency partners. The Journal of Mental Health Training, Education and Practice, 9 (2). pp. 89-100. ISSN 1755-6228

It is advisable to refer to the publisher's version if you intend to cite from the work. http://dx.doi.org/10.1108/JMHTEP-03-2013-0007

For more information about UCLan's research in this area go to http://www.uclan.ac.uk/researchgroups/ and search for <name of research Group>.

For information about Research generally at UCLan please go to http://www.uclan.ac.uk/research/

All outputs in CLoK are protected by Intellectual Property Rights law, including Copyright law. Copyright, IPR and Moral Rights for the works on this site are retained by the individual authors and/or other copyright owners. Terms and conditions for use of this material are defined in the policies page. 


\section{Introduction}

This paper looks at the benefits of personality disorder awareness training across the multi-agency workforce. Multi-agencies is a term we will use throughout this paper to describe organisations that have an interface with people who present with personality disorder outside of secondary mental health services. Personality disorder is defined as 'any disorder in which an individual's personal characteristics cause regular and long-term problems in the way they cope with life and interact with other people and in their ability to respond emotionally' (HM Government 2011a, 2011b).

Organisations include an array of multiple agencies including primary care workers from both mental health and more general backgrounds, criminal justice services, housing providers, social services, third sector providers and mental health charities. The multi-agencies identified as having an interface have been identified based on, high personality disorder prevalence rates in their services and the co-existing difficulties commonly identified with personality disorder that constitute contact with the multiple services. Policy such as the commissioner guidance (DOH 2009) has further assisted the identification of those multi-agencies most likely to come into contact with the client group, highlighting the valuable role multi-agency partners have to play in the effective support and understanding required to effectively work with people with personality disorder.

An innovative Nursing Times award-winning comprehensive multi-agency personality disorder strategy has been developed (Lamph and Hickey 2012). The key aim of this strategy on its commencement in 2010 was to develop a training strategy that would increase multi-agency awareness and knowledge of personality disorder whilst challenging attitudes and improving effectiveness of staff when working with this client group. In order to achieve this, a nationally-recognised personality disorder awareness training model called the Knowledge and Understanding Framework (KUF) was utilised. The KUF has been nationally commissioned by the Department of Health (DOH) and Ministry of Justice (MOJ) (Institute of Mental Health 2013).

This paper will outline the development of the awareness raising multi-agency training initiative. This training initiative, as an early implementer of the KUF is leading the field nationally by raising awareness of the care and treatment for those with personality disorder amongst a multi-agency workforce. To our knowledge this is the first publication outlining results of the KUF.

\section{Background}

Personality disorder has until recent years been one of the most stigmatised and excluded of all mental health conditions (NIMHE, 2003a). A publication entitled 'Personality Disorder: No Longer a Diagnosis of Exclusion' (NIMHE, 2003a) provides recommendations to improve service provision for those affected by personality disorder, identifying amongst other things the need for comprehensive training provision for all agencies likely to be working with 
clients with personality disorder.

A subsequent publication followed entitled 'The Personality Disorder Capabilities Framework - Breaking the Cycle of Rejection' (NIHME 2003b). The aim of this guidance was to create more responsive / effective services and practitioners - reducing staff burnout by raising awareness and encouraging more effective / positive service responses for the client group (Crawford et al 2010; Craissati et al 2011). One of the key challenges within this guidance is to support the drive to break the cycles of rejection that may have been present throughout the individual's life. The focus is to raise levels of understanding and knowledge in relation to interpersonal processes. These cycles of rejection can be reinacted amongst multi-agencies and leads to the repeating of rejection that only intensifies the person's presenting difficulties (Bateman and Krawitz 2013).

People with personality disorder often have experienced abandonment and rejection in their early lives that can lead to them feeling out of synch with other people and not belonging. These difficulties are often manifested by testing out others commitment to them, which can be challenging to workers, especially when they resort to behaviours that could be deemed risky or impulsive. Workers are required to develop a greater understanding and empathy with this client group in order to contain these difficulties and collaboratively work through them by developing a therapeutic relationship based on openness and trust, so that a sense of acceptance and belonging is established (Ladd and Churchill 2012).

Commissioner guidance ( $\mathrm{DOH} 2009)$ recognised that the highest prevalence rates of people with personality disorder (diagnosed and undiagnosed) are identified and being supported in the wider multi-agency system.

In February 2010, local mental health commissioners, appointed 5 Boroughs Partnership NHS Foundation Trust to co-ordinate the development and delivery of a multi-agency personality disorder training initiative. The results of this will be reported in this paper.

The Knowledge and Understanding Framework (KUF) awareness-level programme

The KUF was developed by the Institute of Mental Health in Nottingham and Emergence (a national user-led personality disorder organisation). The awareness-level programme is made up of six online modules and three facilitated group training days. The facilitated training days provide the delegates with a series of power-point presentations; IT training and guided workshops / group activities that are co-delivered by both people with lived experience of personality disorder and multi-agency trainers.

On day one of the course exploration of what personality disorder is, the common misconceptions, stigma and beliefs are explored and time spent introducing delegates to the virtual online learning environment (VLE). 
Day 2 largely explores the development of personality disorder and is explained employing the model of maladaptive schema's. On day 3 , the main focus of the training is exploring how to work more effectively as individuals and as organisations with people who present with personality disorder.

The VLE is employed to support delegates by providing training materials in a modular format. The following modules are complete using this method of learning (see table 1);

Table 1 Online Virtual Learning Environment Modules (VLE)

\begin{tabular}{|l|l|}
\hline Module 1 & What is personality disorder \\
\hline Module 2 & $\begin{array}{l}\text { Labelling, myths and beliefs about } \\
\text { personality disorder }\end{array}$ \\
\hline Module 3 & $\begin{array}{l}\text { Recognising personality disorder: } \\
\text { different perspectives }\end{array}$ \\
\hline Module 4 & $\begin{array}{l}\text { Equipping the organisation to work } \\
\text { with personality disorder }\end{array}$ \\
\hline Module 5 & $\begin{array}{l}\text { Understanding different perspectives } \\
\text { about personality disorder }\end{array}$ \\
\hline Module 6 & Positive outcomes \\
\hline
\end{tabular}

The model of learning is varied between facilitated workshops and the VLE. An example being that module 1-3 are completed online in between day 1 and 2 of the course. The content of these modules is then revisited on day 2 and explored further with the support of the facilitators.

In between days 2 and 3 the modules $4-6$ are complete and subsequently further explored on day 3.

\section{Development of the training strategy}

In the initial phase of this training initiative, there were many concerns and barriers to overcome in order to deliver a comprehensive roll out of KUF to a mixed audience of multi-agency workers. One of the biggest challenges was ensuring adherence to the core principles of a co-delivered training model (service user and staff member trainers on all 3 days) as outlined by the National Institute of Mental Health (2013). Many also believed that delivering KUF locally across a diverse multi-agency population on the scale that we proposed would be unachievable especially given the fact that we were expecting multi-agency workers to deliver the training as part of their already very busy schedules and without financial reward.

In the initial stage our main challenge was to identify people with the capability to deliver the proposed training. People with lived experience of personality disorder (service users) and the multi-agency partners (staff members) who due to their roles were recognised to be working with people with personality disorder were identified. Agencies identified as having a high prevalence of contact with individual's deemed to have or portray recognised characteristics of personality problems were selected (Coid et al 2006: DOH 2009). The 
selection profile is detailed within table 2 and satisfied the requirements of Commissioner guidance ( $\mathrm{DOH} 2009)$ and the standards as outlined by the Institute of Mental Health in Nottingham (2013).

All trainers received managerial support to become involved and became part of a multi-agency personality disorder forum. The focus of this group was to provide trainers with an opportunity to impact on the strategy and drive forward the roll-out of KUF across the local multi-agency system. This forum also provides the KUF trainers with a dedicated arena in which to discuss their experiences, concerns and be supported in their role as KUF Trained Trainers.

An 'Expert by Experience' co-delivery model of training was utilised throughout. This was seen both as good practice but also replicated and adhered to the standards of the national model of delivery (Institute of Mental Health 2013).

\section{Aims of the Service Evaluation Study}

The aim of this study was to evaluate the effectiveness of the 'local' model of mixed multi-agency KUF delivery over a 12-month period. In total we recruited 240 participants from the multi-agency workforce to access the training. Of these 136 completed the training, 82 DNA'd (Did not attend) and 22 DNC (Did not complete) the full programme (see table 2):

Table 2 KUF Delegates April 2011- April 2012

\begin{tabular}{|l|c|}
\hline Multi-Agency Group & Number of Delegates Trained \\
\hline $\begin{array}{l}\text { Group 1 - Mental Health/ Generalised } \\
\text { Health Service }\end{array}$ & 38 \\
\hline $\begin{array}{l}\text { Group 2 - Criminal Justice / } \\
\text { Substance Misuse Services }\end{array}$ & 26 \\
\hline Group 3 - Housing Services & 42 \\
\hline $\begin{array}{l}\text { Group 4 - Other Services and } \\
\text { Agencies including Young Persons } \\
\text { Services }\end{array}$ & 30 \\
\hline Total to complete the training & 136 \\
\hline
\end{tabular}

The training was made up of 12 cohorts and these comprised of a mixture of multi-agencies to encourage different experiences, perspectives and levels of knowledge within each cohort. The rational was to promote networking and also enhance the training experience and knowledge transfer.

The purpose of this service evaluation study is to establish the effectiveness of KUF utilising the innovative comprehensive multi-agency model of codelivery.

\section{Outcome Measures}

The utilised outcome measures were carried out at pre, post and 3 month 
follow up time frames. The Personality Disorder- Knowledge Attitude and Skills Questionnaire (PD-KASQ) was utilised on the recommendation of the central team. Additionally a Visual Analogue Scale (VAS) developed for the purpose of this study was also employed.

Personality Disorder - Knowledge Attitude and Skills Questionnaire (PDKASQ) (Bolton et al, 2010 cited in Shaw et al 2012)

This tool was the recommended tool of choice by the central / national KUF training team who also use this as their outcome measuring tool. This tool is an 18-item questionnaire which includes measurement of factors relating to understanding, capabilities and emotional reactions. Three additional questions were added to the original PD-KASQ for which we have gathered data, which covered issues pertinent to forensic practice.

At each of the different data collection points, one of three versions of the PDKASQ questionnaires was employed with subtle differences in keeping with the differing phases of evaluation. All 21 items were self-rated via the fivepoint Likert scale (ranging from 'strongly disagree' to 'strongly agree'). All questions incorporate and can be coded to the three measured factors of Understanding, Capabilities and Emotional Reactions.

\section{The Visual Analogue Scale (VAS)}

The Visual Analogue Scale (VAS) was developed specifically for the purpose of this study with service user Expert by Experience (EBE) input integral to the shaping of its design. It was designed to ask two simple questions which would enable the service evaluation team to quickly see the efficacy of the training without recourse to complex statistical methods. It was very important that these questions were worded in such a way that were sensitive to the needs of service users delivering the KUF awareness-level training, and did not inadvertently stigmatise the delegates.

After several working discussions, the following questions were utilised. The delegates were asked to place a simple line on a blind visual scale which measured $10 \mathrm{~cm}$ to reflect their answers.

Question 1 - When interacting with people who display powerful emotions, how equipped do you feel you are to deal with this on an interpersonal level? Blind scale of $1-10,1=I$ feel poorly equipped to deal with these situations $10=$ I feel highly equipped to deal with these situations.

Question 2 - When interacting with people who display behaviours that can be challenging, how equipped do you feel you are to deal with this on an interpersonal level?

Blind scale of $1-10,1=I$ feel poorly equipped to deal with these situations $10=$ I feel highly equipped to deal with these situations.

The VAS was utilised at Pre (Day 1), Post (Day 3) (by the completion of forms 
by the delegates) and three months after training (by way of a follow up email). All measures were self-rated by individual delegates.

\section{Results}

Within this section the data results from both the PD-KASQ and VAS shall be reported and discussed.

\section{Visual Analogue Scale (VAS) outcome data}

The VAS results as seen below (See Fig 1 and 2) clearly display an increase in the subjective confidence of delegates' ability to interpersonally manage hostile or highly emotive individuals. Although there was high attrition in those offering three-month follow-up feedback, the continued pattern of improved confidence can still be seen. However, upon purely visual inspection, it could be argued that this change is not as marked as the results for post training. Further analysis would be required to establish if those providing three-month follow-up feedback were those reporting no change or those who could be identified as having lasting improvements in their subjective confidence. The low rate of returned data from the three-month follow-up emails makes the data set less valid. For example, many who did not respond may have still felt increased confidence, but the results were not returned.

Fig 1 (Mean Scores at Pre, Post and Follow up for each of the groups reported)

Question 1: "When interacting with people who display powerful emotions, how equipped do you feel you are to deal with this on an interpersonal level?"

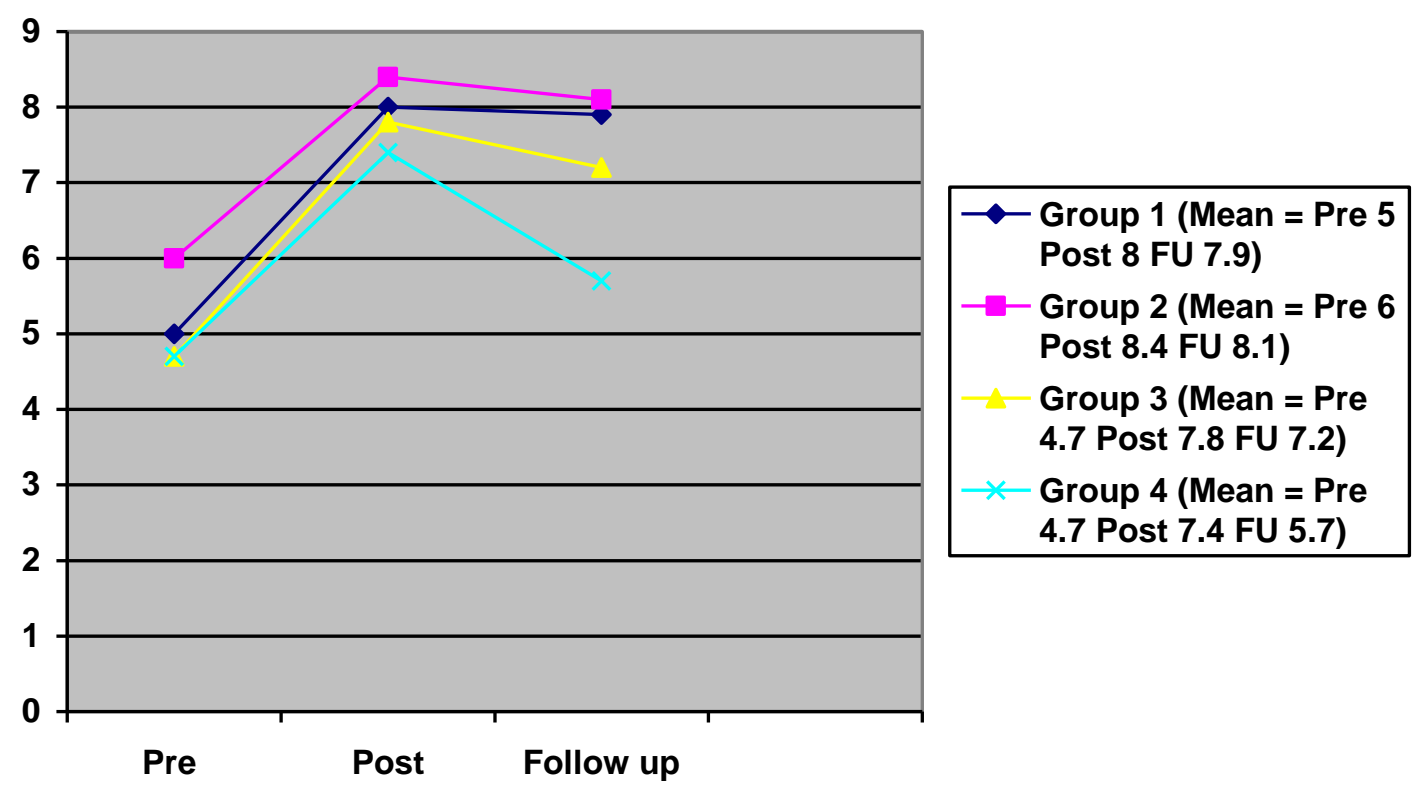


Question 2: "When interacting with people who display behaviours that can be challenging, how equipped do you feel you are to deal with this on an interpersonal level?" VAS Results (mean scores reported)

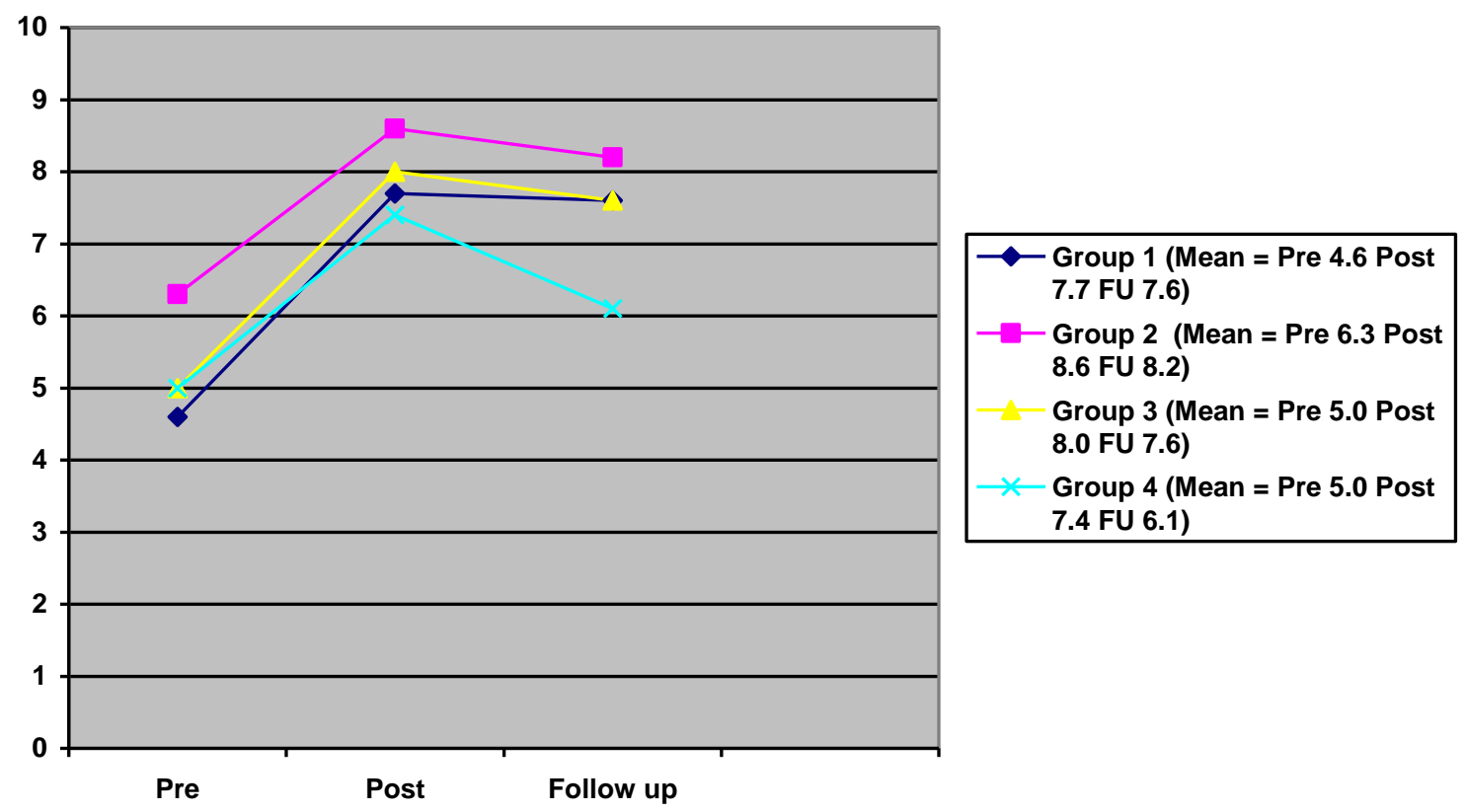

At the pre assessment stage, it can be seen that all groups started the training with a lower subjective confidence which increased at both post training and follow up intervals for both questions. Group 4 was made up of 'other services and agencies' including young-persons. This group appear to have had the least durable effect and group 2 which was the criminal justice workers having the most durable effect at follow up with only a slight decline identified.

Groups 1 and 2 where made up from a more professionally qualified group. This has potential to explain the more beneficial results from the training at follow up as the majority of the delegates had a recognised core profession in health care or criminal justice. In contrast in groups 3 and 4 a large proportion of the delegates did not hold a core professional qualification which may provide evidence of a reduced ability to retain the information and put into practice the learning post training and measures at follow up.

\section{PD-KASQ outcome data}

PD-KASQ data was analysed using SPSS (v.18) for Windows to ascertain differences between the pre, post and follow-up phases on the three subscales (understanding, capabilities and emotional reactions). The five-point Likert Scale data was analysed at the interval level. Scores ranged from strongly disagree (1) to strongly agree (5) and a composite score (mean) was calculated from the items (6) in each sub-scale. 
Table 3. Mean (SD), N on each sub-scale at pre, post and 3 month follow-up

\begin{tabular}{|l|l|l|l|l|l|l|}
\hline Sub-scale & $\begin{array}{l}\text { Pre- } \\
\text { training }\end{array}$ & $\mathbf{N}$ & Post-training & $\mathbf{N}$ & $\begin{array}{l}\text { 3 month } \\
\text { follow-up }\end{array}$ & $\mathbf{N}$ \\
\hline Understanding & $2.74(.56)$ & 152 & $4.03(.40)$ & 97 & $3.34(.26)$ & 24 \\
\hline Capabilities & $3.21(.51)$ & 143 & $3.65(.42)$ & 95 & $3.38(.39)$ & 23 \\
\hline $\begin{array}{l}\text { Emotional } \\
\text { reactions }\end{array}$ & $3.63(.47)$ & 143 & $4.12(.46)$ & 97 & $3.02(.32)$ & 23 \\
\hline
\end{tabular}

Table 4. Mean (SD), N on each sub-scale at pre, post and 3 month follow-up of complete sets of responses

\begin{tabular}{|l|l|l|l|l|l|l|}
\hline Sub-scale & $\begin{array}{l}\text { Pre- } \\
\text { training }\end{array}$ & $\mathbf{N}$ & Post-training & $\mathbf{N}$ & $\begin{array}{l}\text { 3 month } \\
\text { follow-up }\end{array}$ & $\mathbf{N}$ \\
\hline Understanding & $2.59(.41)$ & 19 & $3.94(.34)$ & 19 & $3.30(.27)$ & 19 \\
\hline Capabilities & $3.27(.38)$ & 19 & $3.68(.27)$ & 19 & $3.39(.32)$ & 19 \\
\hline $\begin{array}{l}\text { Emotional } \\
\text { reactions }\end{array}$ & $3.61(.46)$ & 20 & $4.08(.43)$ & 19 & $3.03(.30)$ & 20 \\
\hline
\end{tabular}

A series of Friedman, non-parametric one-way repeated measures analysis of variance were used to consider the data as a whole, across all three different timescales. This test takes into account individual differences and only uses whole sets of data (where all participants have answered all of the questions). The test is also more appropriate to compare changes in scores across time periods when response rate is low to avoid inflated $p$ values.

Following the Friedman tests, Wilcoxon Signed Tank tests with Bonferroni correction applied at a significance level of .017 were generated to consider which specific means differed between the different training times within each sub-scale. The means and standard deviations at each training phase are presented in Table 3. Table 4 demonstrates the means and standard deviations in terms of the data taken as a whole set and incorporates only the participants who responded on all three occasions.

\section{Understanding sub-scale}

There was a significant difference between the scores (pre, post, follow-up) on the understanding sub-scale $\left[\left[\chi^{2}(2)=36.11, p<.05\right]\right.$

Wilcoxon Signed Ranks test found that there was a significant difference on the understanding sub-scale between pre-training and post-training $[z=-8.38$, $p<.017]$ and between pre-training and three-month follow-up ( $z=-3.98$, $p<$.017] However, between post-training and follow-up there was a significant reduction on the understanding sub-scale $[z=-3.94, p<.017]$.

On the understanding sub-scale, pre-training to post-training and pre-training to three-month follow-up the results are clearly positive. However between post-training and three-month follow-up the scores went down which may be due to a lack of longer term impact the training has on understanding. A 
solution to this may be to provide more handout materials or refresher information packs or training in the future.

\section{Capabilities Sub-Scale}

There was a significant difference between the scores on the capability subscale $\left[\chi^{2}(2)=14.73, p<.05\right]$. Wilcoxon Signed Ranks Test yielded a significant difference on the capabilities sub-scale between pre-training and post-training $[\mathrm{z}=-5.80, \mathrm{p}<.017]$ and no significant difference between pre-training and follow-up $[z=-1.62, p=.105]$. There was a significant reduction in the mean score between post-training and follow-up on the capabilities scale $[z=-2.79$, $\mathrm{p}<.017]$.

The results on the capabilities sub-scale, pre-training to post-training are also clearly positive. At pre-training to three-month follow-up results are positive but not significantly. Once again between post-training and three-month follow-up scores went down again, this being indicative of limited durability of the training impact which further supports the need for ongoing refreshers or systems built into the working structures of the multi-agency teams. This could be achieved via regular case supervision in which personality disorder related issues are discussed. A further review of durability would be of particular interest to establish if the reduction in capabilities continues as time post training goes on or stabilises.

\section{Emotional Reactions Sub Scale}

A significant difference was also found on the emotional reaction sub-scale $\left[\chi^{2}\right.$ $(2)=24.03, p<.05]$. Wilcoxon Signed Ranks Test found a significant difference between pre-training and post-training $[z=-7.39, p<.017]$. There was a significant reduction on the emotional reactions scale between pre-training and follow-up $[z=-3.14, p<.017]$ and a reduction of mean scores between post-training and follow-up $[z=-3.94, p<.017]$.

On the emotional reactions' sub-scale, pre-training to post -training results are positive. Between pre-training to three-month follow up scores went down. Post-training to follow up scores also went down. It is clear that the least impressive impact can be seen in this the emotional reactions sub-scale however the KUF is designed as a knowledge and awareness course not to specifically or intensely focus on training people with skills to develop the interpersonal attributes required to manage their own emotions. The further development of a more focussed programme of training that could be used as a skills escalator from awareness-level training may therefore be beneficial.

In summary of the three sub-scales, the emotional sub-scale seems to have less positive results in general when compared to capabilities and understanding, except at the timeframes between pre-post training. The capabilities and understanding sub-scales are more positive, but there seems to be a clear pattern of reduced outcomes in the phase between post training - three-month follow-up, with scores going down. This could be because the information at post-training is fresh and over time it reduces. It may also be 
due to the lack of readily available resources to refresh past delegates memories. It should however be noted that outcomes are consistently positive when compared to baseline pre-questionnaires.

Accessibility to the online learning licence, provided by KUF are closed as per Institutes of mental health's contract one month after completion of the course. Therefore longer term access or refresher sessions may reduce the decline if past delegates were able to refresh and revisit the materials. Further investigation to explore if the decline continues in results over a longer posttraining period is therefore necessary. If the reduction stabilises one could argue that in the longer term the effect remains improved compared to baseline hence showing a positive lasting.

\section{Additional questions pertaining to offenders}

Many of our training delegates work regularly with people who may have offending histories or are specifically enrolled onto the training due to the fact they work within a criminal justice settings. Due to the high prevalence of personality disorder within the offending population it was important to utilise and report the specific questions that are pertaining to the offending population separately (see table 5 and 6).

Table 5 Results relating to questions 19, 20 and 21 pertaining to offenders (taken as a sub-scale):- Means (SD), $N$

\begin{tabular}{|l|l|l|l|l|l|l|}
\hline & $\begin{array}{l}\text { Pre- } \\
\text { training }\end{array}$ & $\mathrm{N}$ & $\begin{array}{l}\text { Post- } \\
\text { training }\end{array}$ & $\mathrm{N}$ & $\begin{array}{l}3 \text { month } \\
\text { follow-up }\end{array}$ & $\mathrm{N}$ \\
\hline $\begin{array}{l}\text { Offending } \\
\text { sub-scale }\end{array}$ & $3.07(.69)$ & 147 & $3.73(.60)$ & 98 & $3.81(.42)$ & 23 \\
\hline
\end{tabular}

Table 6. Results relating to offenders from the complete response set

\begin{tabular}{|l|l|l|l|l|l|l|}
\hline & $\begin{array}{l}\text { Pre- } \\
\text { training }\end{array}$ & $\mathrm{N}$ & $\begin{array}{l}\text { Post- } \\
\text { training }\end{array}$ & $\mathrm{N}$ & $\begin{array}{l}3 \text { month } \\
\text { follow-up }\end{array}$ & $\mathrm{N}$ \\
\hline $\begin{array}{l}\text { Offending } \\
\text { sub-scale }\end{array}$ & $3.04(.43)$ & 19 & $3.82(.42)$ & 19 & $3.89(.40)$ & 19 \\
\hline
\end{tabular}

A Friedman, non-parametric one-way repeated measures ANOVA indicated that there was a significant effect for training time (pre, post, follow-up) on the offending sub-scale $\left[\chi^{2}(2)=24.03, p<.05\right]$

Wilcoxon Signed Ranks test, with Bonferroni correction post-hoc tests indicated that there was a significant difference between pre-training and post-training $(z=-6.76, p<.017)$ and between pre-training and three-monthfollow up $(z=-3.72, p<.017)$. There was no significant difference between post-training and three-month follow-up $(z=-.55, p=1.0)$.

Regarding questions 19,20, 21 - results are all positive between the different time scales so this was really successful. There was an increase in mean 
scores between post training and three-month follow up, but this wasn't statistically significant.

Kirkpatrick (1998) identified 4 different levels of evaluating training programmes, with the first level being the most basic but very important level of training evaluation. This is called the 'Reaction' level and fundamentally measures trainee's satisfaction. As can be seen below trainee satisfaction was consistently positive throughout the course of this study (see figure 3). The other levels include level 2 'Learning' were the focus is upon knowledge increase and level 3 'Behaviour' which is focussed upon behavioural change and impact on individuals work.

Within this paper we have evaluated the training utilising levels 1, 2, 3, however the most robust level of training evaluation has not been explored within this paper, which is level 4 'Results' and pertains to the organisational impact of the training. Unfortunately a high proportion of mental health training evaluations fail to go beyond level 3 evaluations (Bailey 2012) and in this particular study, this hasn't been achieved do to the vast array of different organisations that took part and the scale of the task.

Fig 3 (below) illustrates data collected from the post-training PD-KASQ, outlining an overall appropriateness and experience of the training. From these results it is evident that overall the delegates 'strongly agreed' or 'agreed' that the training was clear, appropriate and relevant to their work.

Fig 3-PD-KASQ content relevance feedback

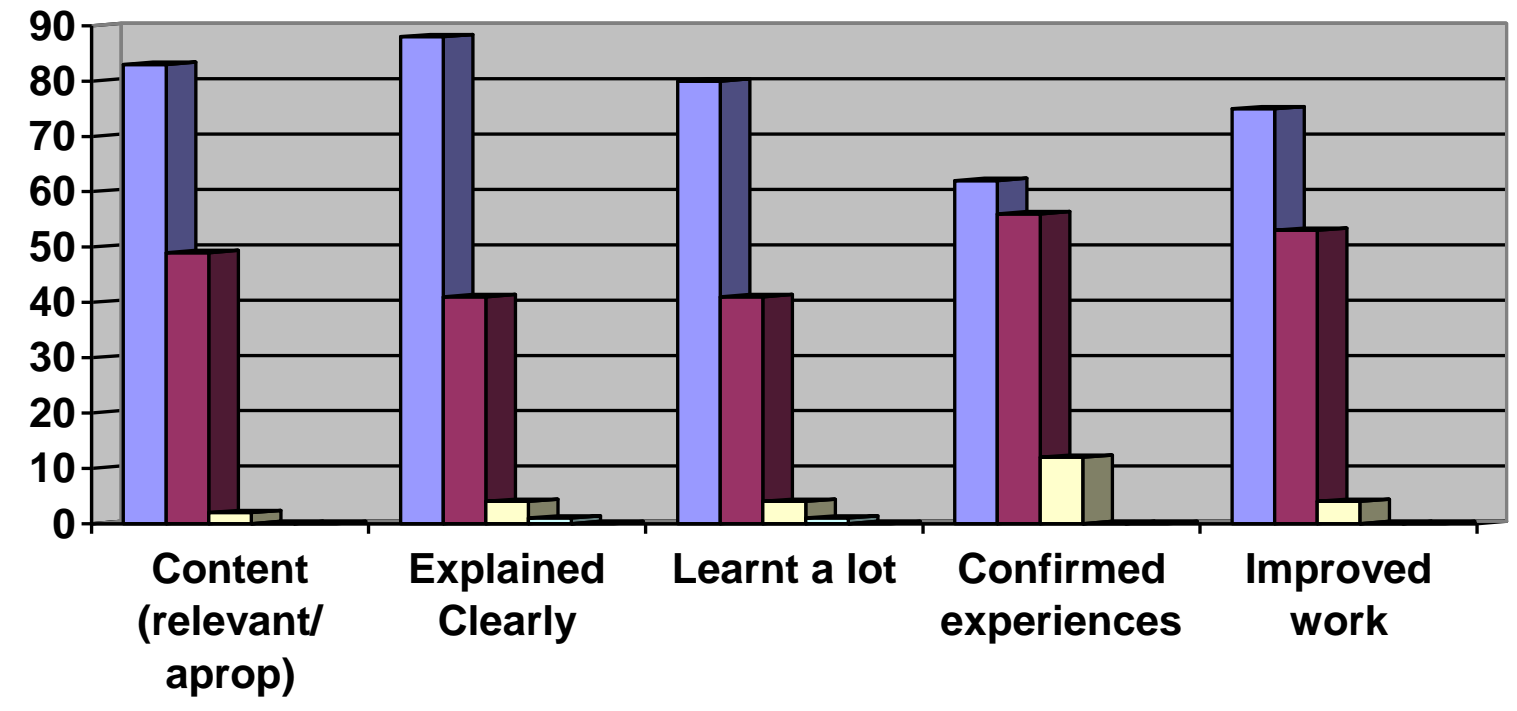

$\square$ Strongly Agree $\square$ Agree $\square$ Uncertain $\square$ Disagree $\square$ Strongly Disagree

\section{Conclusions / Analysis}

This innovative roll-out of KUF training provides evidence that a comprehensive multi-agency roll out of KUF is achievable and can provide statistically significant positive results that display the effectiveness and 
The high demand / uptake of this training and managerial support of the multiagencies provides evidence that multi-agencies that interface with people with personality disorder do require and embrace the opportunities to raise their awareness of personality disorder and that it is appropriate and highly relevant. Recruitment to fill training places was not difficult however the low uptake and none completion rate was higher than we would have expected. This could be attributed to the need to complete all three days, as any missed attendance results in people not being able to complete the course in keeping with the guidance set out by the Institute of Mental Health (2013).

Our findings and experience provides evidence that multi-agency partners from a variety of professional backgrounds can co-deliver training effectively in partnership with people with lived experience of personality disorder. This shared model of working, where professional and service user work as colleagues, in itself helps to deepen understanding, challenge stigma and alter attitudes with regards to personality disorder. It involves a collaborative learning process that is referred to as 'interdisciplinary education and training' (Bailey 2012). The training delegates have particularly welcomed the opportunity to work with a service user in a safe, supportive and educational environment. It must also be noted, many training delegates have via this course gained new contacts, improved insight into other agencies and networking opportunities which they previously did not have due to the mixed multi-agency cohort model we employed.

Overall our data findings are positive particularly when comparing pre and post-results and the pre and follow-up results. However there appears to be an apparent peak in results post training which could be attributed to the fact that knowledge and understanding is recent and fresh in the delegates mind. Positive results are still reported at 3 month follow up, despite the low response rate. There does appear to be a slight decline in the follow up results when compared against the post training results. Access to the online virtual learning modules are cut off one month after completion of the course due to the KUF licence agreement. Longer term access may reduce the decline if past delegates where able to refresh and revisit the materials.

As our follow-up was at three months, which is a relatively short-time span post-training. It would be of great interest to see in the future if the decline continues. If this was followed up and if this pattern continued, this could provide us with evidence to support the development of refresher courses.

In the future, due to the multi-agency design of this service evaluation, comparisons of the different sectors, agencies and occupations involved, could also be explored further to establish what multi-agency areas the training has had the most effect and impact upon. The dataset obtained during this service evaluation study could also be subjected to a number of qualitative methods that have not been reported in this paper. A further review of the organisational impact of the training would be valuable in 
providing further evidence of the effectiveness and impact the KUF has had across the multiple agencies involved in the study and subsequent training.

The results obtained here provide a basis to inform future roll-out of the KUF to multi-agency partners in year two locally however can also can be used to provide leverage for further roll-outs of personality disorder awareness training (KUF) in other multi-agency areas across the country.

\section{Recommendations}

With minimal investment, vision and clear leadership a comprehensive multiagency roll of KUF is achievable. The co-delivery of training has proven to be a very effective model of training, with consistent feedback comments complimenting the uniqueness of the training teams mixing multi-agency staff members with people with lived experience of personality disorder to deliver the course.

Furthermore the positive transformational effects that delivering the KUF training has had upon service users with lived experience of Personality Disorder is notable. Without exception, service user trainers have reported that delivering the KUF training has not only been personally empowering, but has also helped to destroy stigma between service users and 'staff'. This may be attributed to the impact empowering people with lived experience has on their sense of belonging and providing meaningful social contributions consistent with what is reported by Ladd and Churchill (2012). Consideration of the module feedback forms that delegates completed post training also supports the co-delivered benefits reported within this paper.

Managerial support and engagement of multi-agencies is necessary in order to generate interest and can be achieved by selling a vision that enables agencies to see the specific benefits that raised awareness of this client group can have, that will impact positively on their services. Interested and passionate multi-agency champions should be identified who are keen to learn more about the condition.

KUF has shown to have good results in raising awareness however further development of specific skills-based training may enable multi-agency workers to enhance their interpersonal effectiveness further, when working with people with personality disorder.

A further longer term follow-up review is justified to establish if previous delegates continue to show reductions in outcomes and if they return to baseline pre-training rates or stabilise.

\section{References}

Bailey, D. (2012) Interdisciplinary working in mental health. Hampshire: Palgrave Macmillan. 
Bateman, A, W. and Krawitz, R (2013) Borderline Personality Disorder: An evidence-based guide for generalist mental health professionals. Oxford: Oxford University Press.

Coid, J., Yang, M., Tyrer, P., Roberts, A. and Ullrich, S (2006) Prevalence and correlates of personality disorder in Great Britain.. British Journal of Psychiatry. 188: 423-431.

Craissati, J., Minoudis, P., Shaw, J., Chuan, S, J., Simons, S. and Joseph, N (2011) Working with Personality Disordered Offenders: A Practitioners Guide. Ministry of Justice: Crown Copyright.

Crawford, M, J., Adedeji, T., Price, K. and Rutter, D (2001) Job Satisfaction and Burnout Among Staff Working in Community-Based Personality Disorder Services. International Journal Social Psychiatry. 56: 196-206.

Department of Health (DOH) (2009) Recognising Complexity: Commissioner guidance for personality disorder services. London: $\mathrm{DOH}$.

HM Government (2011a) No Health without Mental Health: A CrossGovernment Mental Health Outcomes Strategy for People of All Ages. London: The Stationery Office.

HM Government (2011b) No Health without Mental Health: Delivering Better Mental Health Outcomes for People of All Ages. London: The Stationery Office.

Kirkpatrick, D, L. (1998) Evaluating Training Programmes (The Four Levels) $\left(2^{\text {nd }}\right.$ Ed) San Francisco: Berrett Koehler Publishers, Inc.

Ladd, P, D and Churchill, A (2012) Person-centred diagnosis and treatment in mental health. London: Jessica Kingsley Publishers.

Institute of Mental Health (Nottingham) (2013) The National Personality Disorder Knowledge and Understanding Framework: Prospectus. Nottingham: People, Work and Pictures.

National Institute for Clinical Excellence (NICE) (2009) Borderline Personality Disorder: The Nice Guideline on treatment and management. London: The British Psychological Society.

National Institute for Mental Health in England (NIHME) (2003a)

Personality Disorder: No longer a diagnosis of exclusion: Policy implementation guidance for the development of people with personality disorder. London: NIHME.

National Institute for Mental Health in England (NIHME) (2003b) Breaking the cycles of rejection: The personality disorder capabilities framework. London: NIHME. 
Sampson et al (2006) Personality Disorder and Community Mental Health Teams - A Practitioners Guide Chichester: John Wiley and Sons Ltd.

Shaw, J., Minoudis, P, Hamilton, V and Craissati (2012) An investigation into competency for working with personality disorder and team climate in the probation service. Probation Journal 59 (39) pp 39-48.

\section{Acknowledgements}

No Declaration of Interests. Acknowledgments to the Knowledge and Understanding Framework and the central KUF Team, for the knowledge and support they have provided us with in training up our team and the Personality Disorder Hub service (5 Boroughs Partnership NHS Foundation Trust) for the support and expertise they have provided as a key partner / collaborator in support of this strategy.

\section{Key Points}

- Multi-Agency Partners can effectively deliver KUF

- KUF appears to have positive impact on knowledge, attitudes and stigma for multi-agency workers

- KUF also increases subjective confidence of workers' interpersonal effectiveness when working with people with both emotional difficulties and challenging behaviours

- A comprehensive roll-out of KUF training is achievable

- Multi-agency staff have embraced this way of working and supported the process based on the benefits they feel they will get back from involvement

- Multi-agencies do see personality disorder as their business. This can be seen in the support achieved from multi-agency trainers and also in the interest expressed from delegates. 